\title{
¿Súbditos o ciudadanos? \\ De la crítica libertina al programa ilustrado
}

http://dx.doi.org/10.5209/rev_INGE.2011.n5.36226

\author{
Pedro LOMBA FALCON \\ $\mathrm{UCM}$ \\ (pedro.lomba@filos.ucm.es)
}

\begin{abstract}
RESUMEN
En este trabajo se intenta trazar la génesis de algunas posiciones ilustradas vinculándolas con ciertas ideas nucleares del libertinismo erudito de la primera mitad del siglo XVII, subrayando a la vez que dicha continuidad puede establecerse aun cuando el libertinismo es esencialmente refractario a toda práctica cívico-política del tipo de las que serán desarrolladas por los ilustrados del XVIII. Ensayamos una solución a esta aparente paradoja señalando cómo los conceptos de plebe, soberanía y absolutismo, entre otros, sufren modificaciones sustanciales de un siglo a otro
\end{abstract}

PALABRAS CLAVE: Libertinismo; plebe; legitimidad; teología política; publicidad

\begin{abstract}
In this paper we try to analyze the genesis of some enlightened positions by linking them to some core ideas developped by the french libertinage érudit of the beginnings of XVIIth century. In doing so, we underline at the same time the fact that this libertinage is totally contrary to every single practice, political or social, similar to those that will be developped by the philosophers of Enlightenment during the XVIIIth century. This sort of paradox is solved by trying to understand how the concepts of Plebs, Sovereignty and Absoltism, among others, have change their form or structure between both centuries
\end{abstract}

KEY WORDS: Libertinage; plebs; legitimacy; political theology; publicity

«El hombre de la Edad de Oro honraba la fidelidad y la rectitud de forma espontánea, sin ley que le obligase. Castigos y miedos no influían en su conducta. En ese siglo feliz no había que prestar atención a amenazadores edictos, ni la turba miraba con temor suplicante la fisonomía del juez, sino que sin jueces se sentían seguros. Intacto en los montes, el pino aún no había descendido a las líquidas ondas en forma de barco para visitar un mundo extraño»

(Ovidio, Las metamorfosis, I, fab. 5)

Tal vez los orígenes de la Ilustración, en tanto que movimiento crítico y por tanto emancipatorio, puedan localizarse_como de hecho se han localizado a menudo_en el momento mismo en que surge la filosofía. Sin embargo, quisiera esbozar aquí algunas notas acerca de una escuela de pensamiento-el libertinismo erudito de la primera mitad del siglo XVII-que constituye, de manera explícita y estrictamente material, una verdadera semilla de la que acabará brotando la actitud crítica ilustrada tal como ésta toma cuerpo a lo largo del XVIII. Se trata, sin duda, de un complejo movimiento intelectual ${ }^{1}$

\footnotetext{
${ }^{1}$ Sobre la complejidad de este movimiento, así como acerca de las cautelas metodológicas que se han de tomar para establecer las distinciones necesarias entre los distintos tipos de libertinismo señalados, y
} 
que anuncia y prepara muchas de las posiciones teóricas más generales de la Ilustración. Y ello pese a que, paradójicamente en apariencia, es del todo ajeno a la voluntad de intervención práctica que define o acompaña a esta última, sobre todo por lo que se refiere a la publicidad y difusión de las ideas y, en consecuencia, a la generalización de la educación. Ciertamente, un anuncio o una preparación de tesis o de actitudes nuevas no es nunca una mera anticipación...; es más bien un elemento que acelera el advenimiento de éstas, potenciando así su fuerza.

El libertinismo se presenta como un verdadero antecedente de la crítica ilustradala posición intelectual de ambos movimientos es convergente en un grado muy elevadomostrándose, no obstante, refractario a su impulso emancipatorio-sus posiciones políticas son casi del todo divergentes_- La aparente paradoja queda cifrada, pues, en que una posición teórica en principio muy similar, aunque dada en dos épocas distintas, parece capaz de generar prácticas antagónicas; su solución-provisional, como todas las ensayadas desde la historia de las ideas_reside en la constatación de que lo que determina las derivas de posiciones intelectuales más o menos congruentes en períodos distintos es, quizás, la diferencia de las coyunturas políticas, o, mejor, la diferencia en las maneras como éstas son percibidas y valoradas. Anticiparé la tesis que quiero poner a prueba en estas páginas. Mi propósito es el de esbozar algunas ideas acerca de la operación fundamental que determinará la transformación del movimiento crítico libertino en el impulso emancipatorio ilustrado: la ruptura de una convicción firme y tajante, de carácter negativo, a propósito de la multitud y, por consiguiente, de la publicidad de las ideas. El vulgo, piensa el libertino, vive en la ignorancia y la imaginación como en su medio natural; la única actitud pública que cabe ante la plebe, así pues, es la alimentación consciente y constante de sus ilusiones; dicho a la inversa, la sola idea de difundir el saber entre la turba se presenta como algo ciertamente impensable. Esta concepción en la que los términos «multitud», «vulgo», «plebe» y «turba» son perfectamente intercambiables, es directamente subsidiaria de la necesidad y de la deseabilidad que durante la primera mitad del XVII se atribuye a la organización política del absolutismo—-cuanta mayor distancia se interpone entre el súbdito y el soberano, más sobredimensionada queda la figura de este último-. Pero lo sorprendente es que esta convicción define en sus actitudes y estrategias a esos textos libertinos franceses del siglo XVII, Madrid, Antonio Machado Libros, 2009, 9-38. 
mismos libertinos que, sin embargo, configuran con su escritura muchos de los análisis críticos que darán su fisonomía propia a una Ilustración europea radicalmente construida contra una concepción absoluta de la soberanía forjada mientras ésta ha sido percibida, también por los libertinos eruditos, más como una solución que como un problema. Lo realmente sorprendente, por tanto, es que a pesar de la mencionada manera de percibir a aquélla, y a pesar de su consiguiente defensa, la eclosión del libertinismo supone el comienzo de la imparable destrucción de un mundo mediante la dinamitación de su sentido filosófico común. Destrucción ésta que sólo podrá ser consumada cuando la crítica libertina se acompañe de una decidida voluntad de intervención práctica. Es decir, cuando sea sometida a un cierto proceso de transformación que, sin embargo-y ésta es la paradoja a la que me refiero y que deseo señalar en estas páginas—, preservará intactos muchos de sus posicionamientos teóricos fundamentales. La Ilustración, pues, como mutación genética del libertinismo erudito...

No será del todo inútil, para evitar los problemas que suscita la definición de un movimiento tan complejo intelectualmente como el que nos ocupa, demorarnos un instante en el sentido y los envites de esa erudición que se le atribuye. Pues es la peculiaridad de ésta lo que configura al libertinismo como firme voluntad de crítica, como actitud cuyo sentido último, cuyo emblema común, es la sumisión de la doxa filosófica, ética, teológica y política del siglo del absolutismo a una crítica libre, insumisa respecto de toda forma de autoridad ajena o externa a la racionalidad misma.

Importa, pues, comenzar subrayando que la relación que dicho movimiento mantiene con la erudición que lo califica, lo desmarca tajantemente de los usos más comunes que hasta los siglos XVI y XVII se han hecho de la cultura del pasado. Si algo confiere unidad al heterogéneo conjunto de pensadores que lo conforma-deístas, escépticos, materialistas, ateístas-, eso es en primer lugar su entrega a un trabajo de recuperación de textos, autores, topoi, que hasta el momento han sido considerados menores y desechados como absolutamente irrelevantes o por completo abominables y marginales. Recuperación, pues, de autores, tradiciones y textos abominables y marginales porque violentamente abominados y marginados. El saber libertino, dicho de otro modo, desdeña las fuentes que han contribuido decisivamente a la construcción de aquella doxa triunfante. Así, por lo que se refiere a la Antigüedad clásica, hace un uso de ésta 
totalmente ajeno al propio de determinada erudición renacentista-heredero del establecido por algunos Padres de la Iglesia_en virtud del cual la atención a la cultura antigua (de la que sólo parecen visibles ciertas componentes estoicas, platónicas, aristotélicas y neoplatonizantes), y su recuperación para el presente, ha servido casi exclusivamente para vincularla con el cristianismo en apoteosis. De este modo, la cultura antigua quedaba reducida a aquella que podía considerarse como un antecedente, como anuncio de las tesis más indiscutibles del cristianismo, las cuales se habrían abierto paso en la Antigüedad precristiana, en un medio pagano, como a tientas, en una suerte de designio providencialista. La historia de la filosofía existiría así, tan sólo, como historia de la Pia Philosophia ${ }^{2}$. La actitud libertina, sin embargo, es otra; es, de hecho, casi la opuesta. Su erudición se vuelve también hacia Platón, pero hacia el Platón teórico de la política. O hacia Aristóteles. Pero insistiendo sobre todo en un Aristóteles inaudito: el naturalista y defensor de la mortalidad del alma o de la eternidad del mundo. Estudia igualmente a Cicerón, pero al del De natura deorum o el De divinatione; esto es, los escritos ciceronianos en los que se ha guardado la memoria, a modo de síntesis apretadas y no siempre benévolas, de las tradiciones materialistas, epicúreas y escépticas. Al margen de los grandes nombres de la filosofía de la Antigüedad, la atención se centra ahora en la recuperación y análisis de los textos de los que se nutren, por decirlo así, los márgenes o los puntos ciegos del sentido filosófico común de la primera modernidad filosófica: los textos de los atomistas antiguos, de Epicuro, Lucrecio, Plinio, de Sexto Empírico o de Pirrón. Lo que la biblioteca del libertino selecciona de la Antigüedad, por tanto, son escritos y autores en que cobra expresión una saber perfectamente mundano y, sobre todo, natural... Por ello, el cultivo de estas tradiciones convierte a esta peculiar erudición en una actitud intelectual nueva, ajena a la práctica habitual, sancionada por el uso, del conocimiento del pasado. Desde el libertinismo se vuelve hacia autores, temáticas y textos que han fundado sendas verdaderamente perdidas, tradiciones por completo ajenas al universo filosófico que configura el horizonte de sentido del siglo XVII y que hasta entonces han permanecido ocultas, desplazadas, confinadas en el mejor de los casos a una suerte de albañal trasero y

\footnotetext{
2 Sobre esta cuestión han escrito páginas esclarecedoras T. GREGORY, Genèse de la raison classique de Descartes à Charron, París, P.U.F., 2000, 22ss., y M. A. GRANADA, El umbral de la modernidad, Barcelona, Herder, 2000, 15-51.
} 
secreto de la historia. El libertino rebusca incansablemente en el basurero del mundo cultural europeo ${ }^{3}$.

Por lo que se refiere al pasado más inmediato, al renacentista, el uso de la erudición es similar. La selección de los textos y los temas es igualmente cuidadosa: se dejan de lado sus principales componentes místicas y religiosas-incluso las mágicas y herméticas-para privilegiar el naturalismo inmanentista de autores como Bruno, Pomponazzi o Vanini, las reflexiones políticas de Maquiavelo o Guicciardini-esto es, la reflexión que separa con firmeza la política de la ética-, o, muy en especial, el escepticismo relativista de dos de los autores indiscutiblemente más leídos en la Francia del XVII: Michel de Montaigne y, sobre todo, Pierre Charron4.

Pero lo que nos importa aquí es insistir en que cuando el libertino proyecta su mirada hacia el pasado-remoto o inmediato-no lo hace, tampoco él, de un modo neutro, desinteresado, eludiendo compromisos y apuestas, sino que orienta esa mirada tratando de encontrar modelos filosóficos por completo independientes y extraños a los propuestos desde la ortodoxia religiosa, política e intelectual cristiana que configura a sangre y fuego-a una sangre y un fuego que no siempre han sido sólo simbólicos-el sentido común del momento. Esta peculiar mirada, por tanto, se propone encontrar y

\footnotetext{
${ }^{3}$ No es de extrañar, por consiguiente, que algunas de dichas tradiciones «malditas» (el escepticismo y el epicureísmo en particular) hayan podido sobrevivir en los solos círculos en que se han dado las (tristes) condiciones para su supervivencia: en aquellos grupos sociales o profesionales e intelectuales totalmente extraños y extrañados respecto de la normalidad religiosa, política e intelectual de la primera modernidad. En el caso de España, la cuestión es clara. Semejantes tradiciones han sido preservadas sobre todo entre los médicos judeoconversos del XV y, abiertamente, debido a sus difíciles condiciones de subsistencia religiosa e intelectual (y, por supuesto, física: han demostrado sobradamente que la carne humana es combustible), entre los marranos de los siglos XVI y XVII, que las habrían exportado al norte de Europa al mismo tiempo que rebrotaban en Francia.

${ }^{4}$ Los autores clave en la utilización del pensamiento renacentista son Maquiavelo, Vanini y Charron, verdadera tríada inspiradora de una gran cantidad de tesis libertinas. Pero hay que subrayar que ninguno de ellos pertenece en sentido estricto al libertinismo erudito, $\mathrm{y}$, también, que ninguno de los tres comparte, ni mucho menos, las mismas posiciones teóricas. Aun así, desempeñan una función esencial dentro del movimiento que nos ocupa: garantizan la transmisión, y una suerte de continuidad, del pensamiento del Renacimiento, siendo utilizadas sus obras, al igual que los Ensayos de Montaigne (en los que Charron se inspira explícitamente, y de manera que, en muy diversas ocasiones, en pasajes enteros de su monumental De la Sagesse, se entrega a una suerte de «intertextualidad» un tanto escandalosa), como un auténtico reservorio de argumentos y tópicos de los que se apropian los libertinos. A este respecto, escribirá Gabriel Naudé refiriéndose a sus propias fuentes: «Séneca me ha resultado más útil que Aristóteles, Plutarco más que Platón, Juvenal y Horacio más que Homero y Virgilio; Montaigne y Charron, más que todos los precedentes» (Consideraciones politicas sobre los golpes de Estado, ed. esp. de Carlos Gómez Rodríguez, Madrid, Tecnos, 1998, 33-34). El número de reimpresiones de De la Sagesse es casi incontable a lo largo del XVII en Francia.
} 
reactivar un corpus de autores, textos y topoi en función del cual pensar el mundo y al hombre al margen de toda dogmática religiosa, eclesiástica o política establecidas, construyendo así la historia intelectual de aquella cultura que se ha visto confinada a los márgenes invisibles de la tradición que efectivamente ha configurado el presente-o sea, la identidad de los individuos, de los súbditos o sujetos, también de las naciones-de la Europa del XVII. Todo ello significa, muy precisamente, y teniendo en las manos los textos que genera la escritura libertina ${ }^{5}$, la constitución de un precioso arsenal de argumentos con los que desvelar la naturaleza profunda de las supersticiones, los mitos, las tradiciones y ceremonias absurdas en que según ellos consiste toda religión históricamente establecida $\mathrm{y}$, simultáneamente, todo ordenamiento ético, político o jurídico teológicamente legitimado. Lo cual equivale a combatirlas. Al menos en la teoría. Lo que se está constituyendo con esta crítica, por tanto, es una identidad intelectual, ética y política-una identidad, sin más—nueva, inaudita-monstruosa, por tanto-. O al menos la posibilidad de construirla. Una identidad casi impensable en su presente pero cuyo porvenir, pasado un siglo desde el momento en que comienza a forjarse, será largo.

En efecto, en dicha crítica se hace carne un proyecto cuyo futuro será tan largo como dificultoso: el consistente en hacer emerger una racionalidad que someta a su imperio todos los dominios del pensamiento, especialmente la teología y la filosofía recibidas; una racionalidad que rechace toda regla exterior a la razón misma y todo principio de autoridad, proponiendo a la vez-al menos entre los estrechos círculos libertinos; el matiz, como se verá más abajo, es importante—una libertad filosófica sin trabas de ningún tipo. Esta razón crítica, claro está, quedará como refractada con total espontaneidad sobre el campo de la ética y la moral; lo hará configurándose como esfuerzo por construir una ética autónoma, desligada definitivamente de toda dogmática filosófica y teológica. La crítica de la superstición y de la credulidad se prolongará explícita y naturalmente, por ejemplo, en la búsqueda de una moral independiente de los mandamientos transmitidos por Moisés, o ajena a la imitación de Jesucristo, alcanzando de este modo a las raíces mismas de la representación cristiana del mundo, del hombre y de Dios. De esta manera, la razón crítica libertina será esfuerzo sostenido por analizar los

\footnotetext{
${ }^{5}$ Además de la antología citada en la nota 1, en castellano puede consultarse también la publicada en 2008, en Madrid, por Miraguano Editores. En francés, la antología fundamental es la de Antoine ADAM, Les libertins au XVIIe siècle, París, Buchet/Castel, 1974.
} 
mecanismos y el sentido en función de los cuales el espacio conceptual de lo sagrado se ha presentado siempre, casi ineluctablemente, como principio de fundamentación del campo de la filosofía, y, en consecuencia, como eje de todo ejercicio legitimador de la acción y de las formas de organización política de los hombres.

Si esto es así, no cabe duda entonces de que esa reactivación del poder crítico de la razón es eminentemente liberadora: liberadora de la pesada carga de los dogmas, de las ficciones, de la ignorancia. Pero sobre todo liberadora respecto del uso violento que de esa ignorancia, de la credulidad a ella asociada, se ha hecho a lo largo de prácticamente toda la historia por parte de las autoridades políticas y eclesiásticas. Efectivamente, este primado de una razón materialista y escéptica-una razón, pues, que cuestiona, que sopesa, que no es facultad de autoridad, sino de discernimiento y examen-, conduce como de la mano a un relativismo o a una crítica que pondrá en jaque a la amalgama teológico-política del siglo desvelando su verdadera naturaleza oculta. Y lo hará a través de un análisis absolutamente claro, riguroso y libre de la esencia de esa particular simbiosis que desde siempre se ha establecido entre los gestores de lo sagrado—los administradores de sus símbolos y de la economía de sus mandatos-y los poderes temporales. El libertinismo erudito del XVII diseccionará las relaciones entre teología y política-la traslación de los conceptos de la primera al ambito de la segunda para garantizar así sus fines, por emplear la célebre fórmula de Carl Schmitt ${ }^{6}$-, lo cual significa muy precisamente la puesta en cuestión, al menos en la teoría-y es importante insistir en que esto es así, al menos de momento, en la teoría-, de la concesión de todo privilegio a la historia sagrada y a los principios teológicos del cristianismo, los cuales ciertamente ha constituido el cimiento sobre el que se han sustentado y se sustentan en la Europa del siglo prácticamente todos sus ordenamientos normativos, jurídicos y políticos. A nadie

\footnotetext{
${ }^{6}$ Del Carl SCHMITT de Teología politica (Madrid, Trotta, 2009, trad. esp. de Francisco Javier Conde y Jorge Navarro Pérez). Gabriel Naudé será plenamente consciente de que lo que opera como verdadero resorte de la aceptación de la obediencia impuesta por la forma de la soberanía es precisamente esta traslación. Lo dice muy explícitamente en el capítulo 4 de sus Consideraciones politicas sobre los golpes de Estado. Una vez que ha analizado las cinco maneras como los príncipes o sus ministros han sabido servirse de la religión y su cortejo de milagros, ficciones y mandatos (en una palabra, de su espectacularidad y su poderosísimo influjo sobre la imaginación) para poder legislar con alguna garantía, escribe que estos cinco medios están encaminados a lo esencial: «[...] acomodar la religión a los asuntos de la política» (op. cit., p. 194). Sólo este «acomodo» garantiza la aceptación de la legitimidad de la soberanía por parte del pueblo. Naudé, dicho sea de paso, parece ir más lejos que Carl Schmitt en su análisis de la teología política; al menos parece entregarse sin melancolía alguna a su entera desacralización...
} 
extrañará entonces que la crítica de la Providencia divina, de la concepción antropomórfica de Dios y del antropocentrismo-tres de los grandes tópicos del libertinismo a través de los cuales se desarrolla su crítica de la superstición y de la credulidad—se asocie inmediatamente con el análisis de los mecanismos y de los resortes necesariamente secretos de un ordenamiento político, el absolutista, que extrae su fuerza y su legitimidad de un uso de la religión que ya no puede ser considerado más que como engañoso. Las conclusiones son demoledoras: las fábulas, las ficciones, la maleable simbólica en que el libertino cree que consiste toda religión-incluida la cristiana, indistinguible en su esencia de cualesquiera otras formas de superstición-, constituyen según sus análisis otros tantos instrumentos hábilmente forjados, utilizados y administrados por legisladores, profetas y sacerdotes para la conformación del imaginario y, en consecuencia, de las pasiones de los hombres. La naturaleza última de la religión no es otra, por tanto, que la de un instrumento construido por los legisladores, o, en cualquier caso, construido para ser puesto a su servicio. Nada más que un mecanismo, aunque quizás el más esencial por ser el más eficaz de todos, de la configuración de lo político.

La tesis, por tanto, es diáfana en su generalidad. Y su carga crítica poco menos que explosiva: el prestigio y la fuerza de que gozan las religiones se debe exclusiva y esencialmente a resortes sólo humanos. Si ninguna religión positiva encuentra su fundamento fuera de este mundo, ni al margen de las maniobras e intrigas en que consiste la política, tampoco lo obtendrán allí, en unos valores trascendentes al mundo natural o al mundo social, las disposiciones éticas, jurídicas o normativas legitimadas tradicionalmente desde la teología. Ética y política carecen de todo fundamento sagrado; ética y política tienen su origen en la institución de los legisladores; etica y política, en fin, se revelan tras los análisis libertinos como puramente convencionales, humanas e instrumentales...

Sin embargo, la cuestión es ciertamente compleja, pues, como decíamos al principio, la crítica libertina no supone, sorprendentemente en apariencia, ningún impulso emancipatorio, al menos generalizado. La crítica de la estricta identificación u homología de teología y política es aquí sólo teórica, no conlleva paso alguno hacia una intervención práctica que apunte a forma alguna de subversión. ¿Por qué? Lo cierto es que desde este movimiento intelectual no se deja de pensar a la religión y su espectacular séquito de 
mandamientos, ritos, ceremonias, milagros, etc., como otros tantos engaños forjados- $\mathrm{y}$ forjados a sabiendas-para conformar el imaginario, las pasiones individuales, pero también las políticas y sociales del «pueblo»—esto es, la identidad tanto individual cuanto colectiva de los súbditos y las naciones_- En ello reside su eficacia casi absoluta: en su capacidad para homogeneizar imaginación y pasiones, o sea, aquello que por sí mismo, sin determinación extrínseca y disciplinaria alguna, conduce directamente a la descomposición social. Aquello, en definitiva, sin cuya unificación resulta imposible la composición, la unidad política. Parece que no hubiera alternativa posible: omnipresencia en la vida pública de una religión positiva, o ausencia total de organización política.

Así pues, la paradoja parece clara. Por una parte, el esfuerzo libertino converge en sus líneas fundamentales, anticipándolo o preparándolo, con el proyecto ilustrado, o al menos con el de cierta Ilustración: el de la más radical ${ }^{7}$. Pues el análisis de la génesis y los mecanismos de las variedades de la sinrazón y de la credulidad, así como del uso eminentemente político que de ellas se hace, equivale a desvelar que el mundo teológico de creencias, opiniones, dogmas y principios que determina las coordenadas del universo intelectual y práctico de la Europa del XVII está basado en la ilusión, en la inconsecuencia, en la obstinación, y también en el fanatismo; en cualquier caso, en la fuerza y en la violencia_-simbólica pero constante-en que consiste la promoción de una disciplina-la religión cristiana, sea católica o protestante-que se sabe falsa y engañosa. El libertinismo erudito, de esta manera, constituye indudablemente una condición indispensable para que se haga posible el advenimiento de cierto proyecto ilustrado: aquel cuyo programa general consiste en el rechazo-bien sea desde una posición vagamente deísta, o desde otra abiertamente atea y materialista-de cualquier compromiso con el pasado, tratando así de enterrar definitivamente en éste las estructuras políticas y sociales existentes, rechazando toda forma de autoridad eclesiástica, cualquier tipo de jerarquía social, concentración de privilegios o toda forma de sacralización, de legitimación teológica del poder político y social ${ }^{8}$. Todo parece indicar, así pues, que la fuerza de la

\footnotetext{
7 Cf. Jonathan ISRAEL, Radical Enligbtenment. Philosophy and the Making of Modernity, 1650-1750, OxfordNueva York, Oxford University Press, 2001; Id., Enlightenment Contested. Philosophy, Modernity and the Emancipation of Man, 1670-1752, Oxford-Nueva York, Oxford University Press, 2006; Margaret C. JACOB, The Radical Enligbtenment. Pantheists, Freemasons and Republicans, Londres, The Temple Publishers, 2003 (1981).

8 Proyecto ilustrado éste que define en sus líneas más generales a la llamada «Ilustración radical»a que hacíamos alusión y que no es estrictamente coincidente, claro está, con el de la «llustración moderada» (la
} 
crítica aquí esbozada es la fuerza imparable de una voluntad de subversión de todo un mundo de sentido; todo parece señalar que la voladura de las estructuras intelectuales y políticas del absolutismo-del Antiguo Régimen en Francia-sólo requiere de un pequeño paso, de un mínimo gesto que encienda la llama capaz de arrasar ese universo construido sobre unas ficciones_-sobre una violencia_ya insostenibles tras los análisis libertinos. Éstos, más que preilustrados, presentan toda la apariencia de ser protoilustrados, pues ciertamente son la clave para que se haga posible abandonar una situación de sumisión que coincide estrictamente con la permanencia-en este caso, con el confinamiento, voluntario o forzado-en una verdadera minoría de edad de la razón filosófica, ética, teológica y política. Un pequeño paso, un mínimo gesto, decía, que bien pudiera consistir en la movilización de la opinión pública mediante la sencilla difusión de estos análisis. Pero sin embargo...

Sin embargo, para que se haga efectivo el advenimiento de esa Ilustración materialista y radical que acabo de mencionar, para que la actitud crítica libertina sufra la mutación que la transforme en actitud emancipatoria ilustrada, y en actitud radical, se hace del todo preciso, como decía al comienzo de estas páginas, una operación de ruptura respecto de una actitud doble que también define esencialmente al libertinismo. Actitud que se deriva necesariamente de la percepción que en el siglo XVII— tras el largo período de las guerras de religión que han convertido a Europa en un inmenso campo de batalla, desolación y muerte—-se tiene de la necesidad y deseabilidad de la forma absoluta de la soberanía9. Doble actitud a la que aludo, que imposibilita que el libertinismo pueda ser considerado por sí mismo como un movimiento emancipatorio no ya en la teoría-donde parece muy claro que sí lo es—, sino también, eminentemente, en la práctica.

A lo que me refiero es a la doble convicción que imposibilita que los análisis hasta aquí esbozados puedan atravesar el umbral que separa a lo privado de lo público. Pues la

representada por Diderot, Rousseau, Voltaire, Newton, etc.), la cual, según J. Israel, habría aspirado a preservar de alguna manera ciertos elementos, considerados esenciales, de las estructuras antiguas. Cf. Radical Enlightenment, op. cit. 11.

9 Sobre la manera de concebir el absolutismo en el XVII, manera del todo desvinculada de la carga peyorativa que el término adquiere en la escritura de quienes no pertenecen a la época-carga peyorativa que comienza a convertirse en tópica desde el siglo XVIII hasta nuestros días-, cf., entre otros, R. KOSELLECK, Crítica y crisis. Un estudio sobre la patogénesis del mundo burgués (trad. esp. de Rafael de la Vega y Jorge Pérez de Tudela), Madrid, Trotta, 2007, y S. TOULMIN, Cosmopolis. The Hidden Agenda of Modernity, Chicago, The University of Chicago Press, 1992 (1990). 
escritura libertina nace con la vocación de no ser difundida, de hurtarse a la educación generalizada de ese pueblo que padece en sus carnes los engañosos poderes de la ficción y las pasiones y cuyo imaginario es conformado en consonancia con su mantenimiento estricto en la ilusión, el engaño y la ignorancia. A lo que me refiero, en fin, es a esa doble convicción que hace de todos estos análisis algo rigurosamente ajeno a cualquier voluntad emancipatoria universal, pues dicha convicción doble impide que sea siquiera pensable la posibilidad misma de construir cualquier tipo autonomía intelectual, ética y política más o menos generalizada, no sólo en la teoría, sino también, y de manera especial, en la práctica.

Debemos subrayar en primer lugar que el libertinismo constituye un verdadero esfuerzo crítico de desacralización de la filosofía, la ética y la política en una época en la que ni lo político ni lo religioso-en perfecta simbiosis para mantener estable una organización de la vida social que evite la confrontación que ha hecho de Europa un auténtico erial de ruinas durante buena parte de los siglos XVI y XVII-pueden soportar un ataque de tan amplio alcance. $\mathrm{O}$, dicho de otra manera, en una época en que política y religión están saldando sus cuentas haciendo prácticamente inviable la publicidad de todo discurso crítico. La actitud libertina hacia la difusión de las ideas que se están encarnando en su escritura no puede sino ser extremadamente recelosa.

El límite práctico que acota en primera instancia al análisis viene impuesto, es evidente, por la necesidad de la prudencia, actitud absolutamente necesaria dentro de un mundo cuya fuerza y sentido han sido configurados de manera que la expresión abierta de determinadas ideas conlleva un riesgo muy elevado de persecución, de prisión, de tortura y de muerte. Riesgo del que el libertino es plenamente consciente y que, en general, pesa demasiado sobre la voluntad de difundir unos análisis que chocan de frente contra un poder político que encuentra en el cristianismo su legitimación y el fundamento de la aceptación de su autoridad. El libertino se ve forzado a inscribirse plenamente en el mundo barroco de la disimulación y la simulación ${ }^{10}$, convirtiéndose en verdadero agente de un trabajo intelectual y cultural inaudito cuyos cauces de difusión han de ser, de

\footnotetext{
10 Sobre este asunto, es fundamental el trabajo de J.-P. CAVAILLÉ, Dis/simulations. Jules-César Vanini, François La Mothe Le Vayer, Gabriel Naudé, Louis Machon et Torquato Acetto. Religion, morale et politique au XVIIe siècle, París, Honoré Champion, 2002.
} 
necesidad, totalmente subterráneos y clandestinos. También, en consecuencia, muy minoritarios. Ahora bien, su aceptación de las reglas que imperan en dicho mundo de la simulación y la disimulación no sólo obedece a las circunstancias históricas del siglo, sino que él mismo las legitima por convicción propia. Por una convicción que podemos llamar interna y que define el corazón de la paradoja de la que hemos partido.

Esta concepción que llamamos interna es la necesaria consecuencia, como apuntábamos más arriba, de la concepción libertina del «vulgo», «plebe», «turba»o «estúpida multitud», como se acostumbra a decir desde este movimiento ${ }^{11}$. Concepción ésta-y es importante señalarlo para deshacer todo equívoco que pudiera salirnos al paso-que nada tiene que ver con un elitismo de tipo económico, social o genealógico, sino que obedece muy estrictamente a criterios epistemológicos: es sólo la excelencia intelectual y moral lo que da forma a la élite o minoría frente a la que se define la «plebe» ${ }^{12}$. Pues bien, lo que nos importa ahora es señalar que semejante concepción es lo

11 François Garasse, padre jesuita, temible y temido apologista de la religión cristiana católica, azote despiadado de los libertinos franceses de la primera mitad del XVII, define a éstos con una maestría y conocimiento sólo posibles en quien ha hecho de su propia vida persecución, vigilancia y denuncia de toda desviación de la ortodoxia. En el momento de desvelar las máximas que los definen, ofrece en primer lugar, utilizando al comienzo un muy retórico estilo directo, las siguientes: «I. Hay muy pocos espíritus refinados [o sea, libertinos] en el mundo, y los estúpidos, es decir, el común de los hombres, no son capaces de nuestra doctrina. Y, por tanto, no hay que hablar de ella libremente, sino que es preciso hacerlo en secreto, y entre los espíritus de confianza y cabalistas. II Los espíritus refinados no creen en Dios más que por comodidad y máxima de estado. III. Un espíritu refinado es libre en su creencia, y no se deja cautivar fácilmente en la creencia común, llena de los pequeños fárragos que son propuestos al simple populacho... VIII. Es verdad que para vivir feliz es preciso apagar y ahogar todos los escrúpulos. Pero, no obstante, se debe no parecer impío y abandonado, por miedo a escandalizar a los simples, o a privarse del trato de los espíritus supersticiosos» (en Antología de textos libertinos franceses del siglo XVII, op. cit. 42-43).

${ }^{12}$ No cabe ninguna duda de que no se trata de un concepto económico o sociológico en sentido estricto, o en el sentido en que hoy nos sugiere su antónimo «élite». «Vulgo» o «plebe» no son categorías que remitan a una clase social, a un estrato económico de la sociedad o a las capas de población excluidas de los linajes nobles o aristocráticos que dirigen la vida pública en sentido amplio. El concepto se construye desde un rasero estrictamente intelectual y moral; cualquiera puede pertenecer al «vulgo» y, paralelamente, cualquiera puede formar parte de la élite intelectual: sólo los méritos propios deciden de la pertenencia o no a ella. De hecho, «vulgo» y «mayoría» son conceptos casi indistinguibles, pues la mayoría lo es precisamente por ser ajena a aquello que supone el abandono de la «vulgaridad»: el conocimiento racional, el dominio de las pasiones, la contención y freno de la imaginación en beneficio de la ejercitación del entendimiento, etc. Volvamos a las Consideraciones politicas sobre los golpes de Estado para determinar qué se entiende exactamente por «vulgo» o «plebe» desde el libertinismo erudito. En primer lugar, ésta es descrita aquí en un texto largo y muy bello, aunque realmente crudo: «[...] la plebe es inferior a las bestias, peor que las bestias y cien veces más necia que las mismas bestias, porque las bestias están privadas de razón y se dejan llevar por el instinto que la naturaleza les da como regla de vida, de las acciones, pasiones y formas de actuación, de las cuales jamás se apartan, sino cuando la maldad humana las constriñe a hacerlo. Mientras la plebe (entiendo por esta palabra la turbamulta, la escoria popular, la gente que por uno u otro motivo resulte ser de baja estofa, servil y de condición baja), estando dotada de razón, abusa de ella de mil maneras y pasa a ser, así, teatro ante el que representan sus más exaltadas y sanguinarias tragedias los oradores, predicadores, falsos profetas, impostores, pícaros de la política, revoltosos, sediciosos, 
que determina que el libertinismo, aun siendo revolucionario en la teoría, sea, sin embargo, extremadamente conservador en la práctica, tanto por realismo político, como acabamos de señalar, cuanto por una convicción propia, no impuesta ni forzada, que depende de su concepción de la naturaleza del pueblo; concepción irrenunciable en la medida misma en que es irrenunciable para el libertino la forma absoluta de la soberanía.

Si es cierto que el análisis de la supuesta naturalidad de la simbiosis entre poder político y poder eclesiástico puede conducir-y de hecho conducirá al cabo de un siglo— a una crítica demoledora, también lo es, no obstante, que dicho análisis se lleva a cabo desde la profunda convicción de que los efectos que esa simbiosis produce sobre el común de los hombres, sobre las instituciones y sobre la estructura del cuerpo político, son altamente beneficiosos: es, de hecho, lo único que puede garantizar la buena salud del tejido social. El valor positivo que presentan las creencias religiosas, sus ceremonias, amenazas y promesas, su poder configurador del imaginario y de las pasiones del vulgo, está en su capacidad para generar, garantizar y asegurar la continuidad de la paz civil, de la cohesión de una multitud que el libertino considera-y esto es lo esencial-como sometida naturalmente a la imaginación y, por tanto, a la ignorancia y las pasiones. Esto es, a aquello que sin freno externo de ningún tipo genera de forma necesaria la discordia y la descomposición sociales. El valor positivo de la amalgama teológico-política queda así cifrado en que la religión es percibida como el único instrumento capaz de garantizar la gobernabilidad de un pueblo pensado tan sólo como plebe. El valor enteramente positivo del cortejo de fábulas, ficciones y símbolos en que consiste toda religión está, así pues, en su perfecta eficacia para conducir mansamente al «vulgo» a la sumisión, para generar su voluntaria aceptación de la obediencia, para llevarlo dócilmente al cumplimiento de sus deberes de súbdito, esto es, de miembro o componente de un cuerpo social cuya estabilidad se ha mostrado recientemente_-durante el XVI; la memoria del siglo aún está

\footnotetext{
despechados, supersticiosos, ambiciosos, y, en una palabra, todos aquellos que vienen con un nuevo proyecto. La plebe es comparable con un mar sujeto a toda clase de vientos y tempestades; al camaleón que puede vestirse con cualquier color, excepto el blanco; o a la sentina o cloaca en la que desemboca toda la inmundicia de la casa» (op. cit., cap. IV, 171-172). Este pasaje debe ponerse inmediatamente en relación con este otro, perteneciente al capítulo de la misma obra en el que se señala claramente que nadie debe ser excluido en principio, por razones de índole ajena a la excelencia moral e intelectual, de las más altas funciones de la vida pública: «[...] prudencia y sabiduría no hacen distingos entre las personas, pues igual encuentran habitación en el tonel de Diógenes, en las escuelas, bajo la sotana, bajo unos raídos harapos, que entre las delicias y suntuosidades de un palacio; tan cierto es, que se dice: nescio quomodo factum est, ut semper bonae mentis soror sit pauperitas» (op. cit., cap. V, 218-219).
} 
muy fresca-como extremadamente delicada, en particular en Francia. El valor de la religión, tan criticada en la teoría, está para el libertino en la necesidad de su probada eficacia política. Y su verdadera legitimidad, consecuentemente, en su capacidad para establecer, mantener y asegurar hasta donde es posible la paz civil, para contener las pasiones del común de los hombres, de la «turba» o «plebe», tan peligrosa e inestable como la dinamita y la pólvora que todavía flota en la atmósfera del momento. El valor enteramente positivo de la religión, del cristianismo, por tanto, no está donde comúnmente se piensa que reside; de la destrucción teórica de esta ilusión ya se han encargado los libertinos con sus análisis. Pero ello no significa en absoluto que carezca enteramente de valor. Éste queda cifrado en que posibilita la forja de un fundamento absoluto-ficticio aunque necesario dada la naturaleza del «vulgo» o «plebe»—a las leyes y a la soberanía, promoviendo con ello, simultáneamente, una aceptación, es decir, una sumisión, igualmente absoluta. Pues la religión constituye por su propia forma-como función de su objetivación del bien y del mal, de su amenaza con castigos ultraterrenos, de su promesa de recompensas, de sus genealogías regias, etc.- - un freno para las pasiones de ese «vulgo» sin cuya contención se hace imposible la constitución de un cuerpo político unitario. Su verdadero valor, por tanto, está en que constituye el único medio eficaz para la producción y la reproducción de la sumisión requerida para conformar la unidad de un cuerpo social estable. No otra es la paradoja libertina: aun habiendo denunciado toda religión como invención de hombres hábiles y astutos-los legisladores, indistinguibles de determinados profetas, por ejemplo Moisés, cuyos verdaderos objetivos y funciones quedan así claramente al descubierto ${ }^{13}$ — que han explotado la credulidad y la ignorancia naturales del pueblo, su valor positivo queda fijado en el hecho comprobado, según el libertino, de que sólo a su través se hace posible imponer y legitimar ante este «vulgo», y aun en nombre de una divinidad y unos principios en los que ni los legisladores ni los profetas mismos han creído, un orden político y social digno de su nombre. Tal es el único modo posible de asentar un código de valores morales y de normas jurídicas positivas, y, lo que es quizás más importante, de garantizar su cumplimiento y aceptación

\footnotetext{
${ }^{13}$ La idea vuelve a ponerla en circulación Maquiavelo (Elprincipe, 6), quien retoma de Tito Livio, Ovidio, Plutarco, Cicerón, etc., el tema de la impostura teológico-política, desarrollado en la Antigüedad a propósito sobre todo de Numa Pompilio, primer rey de Roma. Será inútil insistir en que el asunto aparece en prácticamente todos los textos libertinos del XVII, convirtiéndose en un tópico casi de tratamiento obligado.
} 
por parte de una multitud pensada como incapaz esencialmente, por su propia naturaleza, de comprender racionalmente su necesidad. El único—o, en todo caso, el mejor-modo de legitimar aquel código y aquellas normas, es decir, la única forma de invisibilizar esa violencia fundante y constitutiva de unidad de manera que sea voluntariamente aceptada, es el consistente en alimentar la credulidad y la ignorancia que definen la esencia de la «plebe». O sea, el consistente en promocionar lo falso como si realmente fuese manifestación de la verdad.

Se puede decir lo mismo de un modo que tal vez resulte más esclarecedor: la rebelión de un pueblo que es considerado como naturalmente ignorante-rebelión a la que seguramente conduciría la difusión de los análisis esbozados—, no podría dejar de generar efectos enteramente negativos a los ojos del libertino. Pues éste considera que la revuelta de un vulgo que se guía solamente al azar de sus pasiones y de su imaginación; que es por su propia esencia incapaz de alcanzar y asimilar la verdad; que conforma una suerte de rebaño del todo extranjero a la posibilidad de vivir por sí mismo según los dictámenes de una razón que por consiguiente le es extraña y ajena; que, dicho brevemente, está por naturaleza impedido para todo grado de autonomía intelectual y, por tanto, ética y política; la revuelta de un pueblo así concebido, decía, únicamente puede engendrar un mal irremediable sin poder provocar una transformación política positiva. Así pues, la moral y las políticas que deben guiar y conformar a la «plebe» sólo pueden basarse enteramente en la esperanza y el miedo, en la promesa de recompensas y en la amenaza con castigos, en la sanción teológica de los mandatos, en la gestión y configuración estricta, casi milimétrica, de su imaginación y sus pasiones. Es decir, en el conjunto de ficciones y engaños impunemente revestido de sacralidad que según el libertino componen los elementos esenciales de toda religión históricamente establecida. Sólo aquella política teológica puesta al descubierto puede salvar el presente; su bondad, su legitimidad y su eficacia para configurar y domeñar a un «vulgo» de otro modo indomeñable, son rigurosamente indistinguibles. Y de ahí que desde esta escritura se conceda al secreto y la no difusión generalizada de las ideas una importancia más que extrema. Éstas sólo pueden ser compartidas dentro del estrecho círculo de los libertinos, y también-para así potenciar al máximo su utilidad asegurando la producción y la reproducción de la soberanía y la obediencia-por el monarca y las élites dirigentes, a quienes se supone igualmente excluidos del infernal círculo de ignorancia y brutalidad que 
define a la «plebe» haciendo de ella algo esencialmente amenazador y peligroso. Sin duda, los libertinos eruditos tienen plena conciencia de que los hombres de la Edad de Oro que cantó Ovidio-y cuya descripción nos hemos apropiado nosotros como exergo para estas páginas-pertenecen exclusivamente al ámbito de la ficción. La historia y la política, el duro presente del siglo XVII, son, respecto de aquella Edad y aquel espacio, un mundo ciertamente extraño. En el que se ofrece a la mirada del libertino como realmente existente no es la racionalidad, sino «los castigos y los miedos», los «amenazadores edictos», lo que determina la conducta del común de los hombres, la conducta de «la turba» que mira «con temor suplicante» la «fisonomía del juez» ${ }^{14}$.

Todo lo anterior da cuenta del sentido en que la posición libertina se proyecta de un modo en extremo reservado y elitista en la práctica. O sea, explica las razonesteóricas, aunque estrechamente dependientes de razones históricas o materiales-que avalan que no haya desembocado de inmediato en una actitud práctica combativa y plenamente coherente con los principios que se desgajan de sus análisis definiendo su posición teórica propia. Pues lo que funda su actitud retraída respecto de toda intervención pública es su propio reconocimiento de que la difusión de sus ideas sólo podría convocar al fantasma que recorre y agita el siglo: el de la amenaza de descomposición social y nacional que ha atravesado el siglo anterior. La paradoja que señalamos se convierte así en espejo del laberinto que la historia ha hecho del siglo del absolutismo: se denuncia la insolvencia teórica de la sacralización del poder político y eclesiástico, la falsedad de su legitimación—o, mejor, la necesidad de mantener oculta la legitimidad real de dicho poder: la demostrada eficacia de su fuerza, de su violencia, para generar y regenerar la unidad y la obediencia-, pero reconociendo a continuación que la construcción de un nuevo escenario político y social sólo puede equivaler a un retorno a los no muy lejanos tiempos de las batallas y las ruinas. La difusión y publicidad de las ideas, por tanto, no puede considerarse posible. Sobre todo porque no es deseable. No es posible ni deseable el desengaño, la educación del pueblo, a pesar de que se está en posesión de una de las claves teóricas que conduciría a ella. Quizás de la más fundamental.

En cualquier caso, lo que parece claro es que el solo abandono de esta actitud precipitará el advenimiento de esa generalizada revolución teórica, pero también social y

\footnotetext{
${ }^{14}$ Estos entrecomillados pertenecen a la cita de Ovidio que encabeza el presente trabajo.
} 
política, que tanto se ha temido y que dará un rostro propio al siglo de las Luces ${ }^{15}$. Revolución que hará que entre definitivamente en su fase de descomposición ese universo axiológico, político y religioso de la civilización europea del XVII que los libertinos han diseccionado en la teoría, llegando a unos límites hasta entonces insospechados, con su erudición y su escritura subterránea, blindada para ser difundida tan sólo entre una minúscula y erudita minoría. Para que esa difusión se haga extensible a la mayoría, a la «plebe», será del todo necesario pensar a ésta de otro modo. Y para que, a su vez, sea posible este cambio de consideración, será indispensable dejar de pensar la forma absoluta de la soberanía como una solución necesaria, como algo absolutamente deseable frente al retroceso a la barbarie de las guerras civiles de religión que supuestamente supondría su ausencia. Habrá que pensarla, por el contrario, como problema. Dicho a la inversa, concebir al soberano como figura prescindible, pensar la soberanía absoluta como figura en que se encarna la tiranía y la opresión, será la condición indispensable para poder pensar a su sombra, el pueblo, los súbditos, no como «plebe» o «turba», sino como ciudadanía. Pues la igualación e indistinción de esa «estúpida multitud» en la ignorancia, su perpetuo confinamiento en ella, redimensionan prácticamente hasta el infinito la figura del monarca-y también la de su hermano gemelo: el sacerdote-blindando simultáneamente y casi de un modo indestructible la sumisión y la obediencia de esa «plebe». Pensar a ésta de otra manera no significará sino pensarla como capaz de recibir y de aceptar una verdadera educación ética y política; como capaz de recibir y aceptar, por ejemplo, las ideas que se reserva el libertino; como capaz de abandonar por sí misma la minoría de edad en que ha sido mantenida. Es decir, pensarla como no ha podido ser concebida desde el libertinismo.

Sea como fuere, lo que también parece claro es que en la primera mitad del XVII las condiciones materiales para ello no estaban aún lo suficientemente maduras. La mutación genética que transforme al libertino en ilustrado radical deberá esperar a que llegue su momento. La espera no será larga. En menos de un siglo brotará una suerte de entusiasmo revolucionario que llevará a los hombres a pensar que es posible instaurar

\footnotetext{
15 De hecho, como no podía ser de otra manera, las ideas libertinas serán ampliamente utilizadas y reelaboradas en los escritos que realmente llamarán a esa revolución teórico-práctica inconcebible para Naudé, La Mothe Le Vayer, Charron o Saint-Évremond. Me refiero a la auténtica avalancha de panfletos anónimos y clandestinos que inunda los comienzos del siglo XVIII, o a los textos, modélicamente ateos y materialistas o escépticos, de preilustrados tan eminentes, y radicales como el cura Meslier o el barón D’Holbach.
} 
unos tiempos en los que lo realmente existente será una vida generalizada guiada únicamente por los mandatos de la razón; unos tiempos en cierto modo similares a los cantados por Ovidio. Sin embargo, y lejos de la autosatisfacción que supone reconocer unos tiempos y un proyecto con los que poder identificarnos, tal vez debamos preguntarnos si aquel entusiasmo ha cerrado verdadera y definitivamente las puertas de aquel mundo que tan extraño era para los hombres de la Edad de Oro. O si, por el contrario, las Edades de Oro y sus representaciones, todas ellas, no son sino un canto de sirena, una pantalla amable tras la que siempre acecha la barbarie. 